\title{
Rede de apoio social de pacientes com diagnóstico de esquizofrenia: Estudo exploratório
}

\author{
Tereza Efigênia Pessoa Morano Macêdo \\ Universidade Católica de Brasília \\ Cibelle Antunes Fernandes \\ Universidade Católica de Brasília \\ Ileno Silva da Costa \\ Universidade de Brasília
}

\begin{abstract}
Resumo
Este artigo objetivou descrever e analisar a rede de apoio social de pacientes com diagnóstico de esquizofrenia de um Centro de Atenção Psicossocial II (CAPS II) do Distrito Federal, Brasil, por meio da Análise de Redes Sociais (ARS). Observou-se que a maioria consegue retribuir o apoio recebido, especialmente para os membros da família. Estender essa reciprocidade poderia ser uma proposta a ser desenvolvida, a fim de fortalecer as relações para além do âmbito familiar e incentivar melhorias na rede de apoio social. Uma cultura participativa em todos os contextos, nos quais se encontram inseridos os portadores de esquizofrenia, pode contribuir, sobremaneira, para o aumento da autonomia e da autoestima dos mesmos. Verifica-se que é viável, por meio deste estudo, reconhecer as limitações dos pacientes em questão, assim como identificar suas potencialidades.
\end{abstract}

Palavras-chave: apoio social; esquizofrenia; centro de atenção psicossocial (CAPS); reforma psiquiátrica.

\begin{abstract}
Social support network of patients with schizophrenia diagnosis: Exploratory studying. The article describes and analyses the social support network of patients with schizophrenia diagnosis of an attention psychosocial center of the Distrito Federal, Brazil, through the Social Network Analysis. The findings relate that many patients are able to give back the received support, especially to the family members. Therefore, the support reciprocity may be a purpose to be developed, turning stronger the relationships, and motivating improvements on the social support network. A participative culture in all contexts where the schizophrenia has been included may contribute for increasing autonomy and self-steam. Overall, the social support network studying becomes possible through the network evaluation, recognizing the limitations and identifying the potentialities for better changes.
\end{abstract}

Keywords: social support; schizophrenia; attention psychosocial center (CAPS); psychiatry reform.

\section{Resumen}

Red social de apoyo a pacientes com diagnóstico de esquizofrenia: Estudio exploratório. El objetivo de este artículo fue describir y analizar la red social de apoyo a pacientes con el diagnostico de esquizofrenia en un Centro de Atención Psicosocial II (CAPS II) del Distrito Federal, Brasil, a través del Análisis de Redes Sociales (ARS). Se observó que la mayoría consigue retribuir el apoyo recibido, en especial a los miembros de la familia. Prolongar esa reciprocidad podría ser una propuesta a ser desarrollada para fortalecer las relaciones para más allá del ámbito familiar e incentivar mejorías de la red social de apoyo. Una cultura participativa en todos los contextos en los cuales se encuentran los portadores de esquizofrenia puede contribuir, en extremo, para el aumento de la autonomía y la autoestima de los mismos. Se verifica que es viable, por medio de este estudio, reconocer las limitaciones de los pacientes en cuestión, así como identificar sus potencialidades.

Palabras-clave: apoyo social; esquizofrenia; centro de atención psicosocial (CAPS); reforma psiquiátrica.

$\mathrm{O}$ entendimento de uma sociedade adquire-se por meio do conhecimento acerca daquilo que é posto à margem e do que é ou vira alvo de preconceito, e não apenas do que é admirado e exaltado aos olhos do povo. A observação da forma com que as pessoas reagem a tais grupos ou fenômenos, assim como das variadas maneiras de se pensar o marginal, possibilita conhecer o modo como essa sociedade se organiza (Foucault, 1984). Dentre todos os sujeitos que nossa sociedade quer tornar 
invisíveis, cita-se o louco como vítima real dos processos sociais deletérios surgidos ao longo da sua história.

No século XVII, marco da formação industrial, foram criados os grandes estabelecimentos, sem nenhuma intenção terapêutica, para internar todos aqueles que estavam fora da ordem social. No final do século XVIII e início do XIX, como forma de atender às exigências do capitalismo, Pinel soltou todos aqueles aptos ao trabalho e manteve os loucos internados. Dessa forma, tais enclausuramentos transformaram-se em hospitais psiquiátricos, marcando o surgimento da psiquiatria e a ênfase nos distúrbios mentais (Foucault, 1999).

Durante o século $\mathrm{XX}$, os asilos psiquiátricos apresentavam péssimas condições físicas, caráter desumano e ineficácia terapêutica (Foucault, 1984, 1999). No Brasil, pelos idos de 1940, predominavam os hospitais públicos, com $80,7 \%$ dos leitos psiquiátricos do país. Eram referência de assistência os asilos como o Juqueri em São Paulo, o Hospital Nacional dos Alienados no Rio de Janeiro e o São Pedro em Porto Alegre (Paulin \& Turato, 2004). Em consequência a isso, nasceu a Reforma Psiquiátrica (em construção até os dias de hoje) em prol da cidadania e dos direitos do portador de transtorno mental (Fontes, 2007; Paulin \&Turato, 2004; Speck, 1989; Tenório, 2001; Tenório, 2002).

O movimento da reforma psiquiátrica brasileira, que se inicia no final da década de 1970 e se estende durante toda a década de 1980, teve um marco histórico e de legalização institucional de toda a luta com a aprovação pelo Congresso Nacional e sanção do presidente da República, em 6 de abril de 2001, da Lei 10.216, para promover a reestruturação da assistência psiquiátrica no país. O marco decisivo para tal desfecho foi a aprovação do projeto de lei do deputado Paulo Delgado (PT-MG) pela Câmara Federal, em 1989, posteriormente encaminhado para apreciação do Senado e que recebeu então várias emendas e substitutivos (Paulin \& Turato, 2004).

Paulin e Turato (2004) relembram que na década de 1970 o Brasil segue influenciado por propostas preventivista e de psiquiatria comunitária experimentadas na Europa e principalmente nos EUA, tendo como referência os trabalhos de Gerald Caplan, que redirecionam os objetivos da psiquiatria para a saúde mental. A partir desse movimento acrescenta-se como proposta e estratégia terapêutica a ideia de uma ação comunitária, de atenção psicossocial diferenciada que torne possível a interferência nas relações de cunho social, cultural e econômica; e a exigência da sustentação de práticas singulares de cuidado, de acompanhamento e de assistência, com o auxílio da clínica e do contato direto como condição efetiva (Tenório, 2001).

Nesse sentido, na atualidade, o Ministério da Saúde, com base na Lei 10.216/01, presta seu apoio à Política de Saúde Mental, a qual busca consolidar um modelo de atenção aberto e de base comunitária, contando com uma rede de serviços e equipamentos variados: os Centros de Atenção Psicossociais (CAPS), os Serviços Residenciais Terapêuticos (SRT), os Centros de Convivência e Cultura, os Núcleos de Atenção Psicossocial (NAPS), os Centros de Referência de Saúde Mental (CERSAMs) e os leitos de atenção integral (Hospitais Gerais, nos CAPS III) (Tenório, 2001). Esta lei representa o fim do modelo hospitalocêntrico e a implementação progressiva de uma rede multiinstitucional de apoio psicossocial.

Além da influência da psiquiatria preventivista e comunitária, a segunda metade da década de 1970 é marcada por críticas à ineficácia da assistência pública e da política de saúde do governo central. É um período marcado por denúncias de fraude no sistema financeiro de serviços, de abandono, de violência e de falta de cuidado a quem eram submetidos os pacientes internados. Em 1978, cria-se o Movimento dos Trabalhadores em Saúde Mental (MTSM), que por alcançar grande repercussão (por meio de reivindicações trabalhistas), liderou os acontecimentos que levaram a luta até seu caráter antimanicomial. Por meio deste movimento é possível verificar todo o trabalho e esforço realizados pelos profissionais envolvidos na melhoria dos serviços. Mudanças positivas e perceptíveis têm acontecido na assistência em Saúde Mental, incluindo políticas nacionais e internacionais, marcadas por tentativas de inserção de novas e aperfeiçoadas práticas terapêuticas (Fontes, 2007; Kern, Glynn, Horan, \& Marder, 2009; Patterson \& Leeuwenkamp, 2008; Rüesch, Graf, Meyer, Rössler, \& Hell, 2004). Entretanto, segundo Zelst (2009), ainda é frequente assistir à realidade de pacientes com transtornos mentais, especialmente de esquizofrênicos, população em foco no presente trabalho, vítimas de preconceito, de exclusão social, de privação aos sistemas básicos e ao estabelecimento de relações sociais (família, amigos e comunidade).

A esquizofrenia, conforme entendimento atual, é considerada um transtorno psíquico grave, relativamente frequente e de grande importância clínica. Segundo estudos de Barlow e Durand (2008), em escala mundial atinge os valores de $0,2 \%$ e $1,5 \%$ da população mundial total, sendo a prevalência equivalente para homens e mulheres. Esses mesmos autores referem que a expectativa de vida do paciente portador de esquizofrenia é ligeiramente menor que a média, devido ao maior índice de suicídios e de acidentes entre esquizofrênicos.

A Organização Mundial de Saúde - OMS entende a esquizofrenia como o principal transtorno mental, ou grupo de transtornos dos quais as causas ainda estão largamente desconhecidas. Tais causas envolvem uma série de distúrbios do pensamento, da percepção e do comportamento afetivo e social. Considera-se como uma doença universal, visto que nenhuma sociedade ou cultura no mundo tem estado livre da mesma. Produz impacto significativo na vida relacional, social e produtiva dos indivíduos assim diagnosticados, além de afetar o seu regozijo em viver (Barlow \& Durand, 2008; WHO, 1996).

O caráter crônico da doença evolui devido ao aparecimento de sintomas denominados de primeira ordem, de Kurt Schneider (1887 - 1967), envolvendo disfunções cognitivas e emocionais (delírios, alucinações auditivas, difusão do pensamento e vivências de influência na esfera corporal ou ideativa), somados, muitas vezes, aos de segunda ordem (perplexidade, alteração senso perceptiva, alteração no campo dos sentimentos, impulsos ou vontade, empobrecimento afetivo, e alteração do ânimo). Tais sintomas, especialmente os de primeira ordem, geram grande alteração na relação 'eu-mundo', e são marcados pela perda da intimidade e pelo pouco contato com o outro, o que gera o empobrecimento da sua rede social pessoal (Dalgalarrondo, 
2008).

De qualquer modo, em uma perspectiva de psicopatologia sindrômica, citam-se os seguintes critérios diagnósticos para a esquizofrenia, em acordo com a Classificação Internacional de Doenças $-10^{\underline{a}}$ revisão: as distorções do pensamento e da percepção, os afetos inapropriados ou embotados, os comportamentos desorganizados e incompreensíveis, além de possíveis déficits cognitivos (Dalgalarrondo, 2008).

$\mathrm{Na}$ hipótese psicodinâmica, a esquizofrenia é vista como uma manifestação de sintomas advindos de fatores genéticos, biológicos, ambientais e psicológicos, que se acumularam e causaram danos ao funcionamento psíquico. Tais fatores são capazes de causar uma forte carga de ansiedade em momentos em que o sujeito não possui uma sólida estrutura de sustentação egóica. Dessa forma, pensa-se em infinitas possibilidades de combinação entre tais fatores e em diferentes maneiras do sujeito funcionar e reagir às diversas influências, alterando, de forma favorável ou desfavorável, a vulnerabilidade à psicose; e a instalação, de fato, de um ego psicótico (Adrados, 1982; Gabbard, Beck, \& Holmes, 2007).

Por meio de um constructo teórico entre a teoria sistêmica da família e uma possível hipótese sistêmica da esquizofrenia, explica-se que assim como a família se estrutura em função de uma situação, a esquizofrenia também se desenvolve a partir de problemáticas advindas das diferentes etapas do desenvolvimento humano, envolvendo não somente a transmissão genética, mas a história de vida, as situações atuais com as quais o sujeito se depara, além dos tipos de apoio social os quais tem oportunidade de receber.

A temática rede de apoio social tem sido enfatizada com relevância por estudiosos de todo o mundo, em diversos aspectos e contextos diferenciados de vida, no que diz respeito à prevenção ou diminuição do agravamento de doenças, à melhora da qualidade de vida e, em especial, à preocupação com o indivíduo, por meio de atitudes humanistas e integradoras (Furtado, 2006; Landim, Comaru, Mesquita, \& Collares, 2006; Macpherson, 2009; Onocko-Campos \& Zelst, 2009). Retrata "a soma de todas as relações que um indivíduo percebe como significativas ou define como diferenciadas da massa anônima da sociedade" (Sluzki, 1997, p.15), e encontra-se em constante mudança durante a vida, com base nas interações sociais estabelecidas com os diversos membros que se conhece a cada instante.

$\mathrm{O}$ apoio social está relacionado a uma manifestação mais ampla de cuidado a pessoas, ou seja, a uma forma interdependente de dar e receber suporte por meio de práticas sociais que vão além de interesses financeiros e políticos do mercado e do Estado (Fontes, 2007).

De acordo com esse autor, os diversos atores sociais citados na rede social pessoal desempenham tipos predominantes de intercâmbio interpessoal ou funções de rede. A companhia social refere-se ao estar juntos; o apoio emocional conota uma atitude emocional positiva; o guia cognitivo e de conselhos compartilha informações e esclarece expectativas; o regulador social reafirma responsabilidades; e a função de prestar ajuda física, material e de serviços destina-se aos serviços de saúde por meio de conhecimentos específicos.

É urgente e necessária a realização de um trabalho de apoio social, a fim de buscar perspectivas contributivas para a saúde e para o fortalecimento das relações interpessoais, de favorecer o conhecimento de cada paciente por parte dos profissionais de saúde, de possibilitar novas alternativas de tratamento e intervenção, e de facilitar o enfrentamento da doença, assim como de propiciar uma possível reinserção (Fontes, 2007; Meneses \& Sarriera, 2005). "A reinserção assume o caráter de reconstrução das perdas e seu objetivo é a capacitação do paciente para exercer seu direito à cidadania" (Duarte, 2010, p. 16).

O exercício da cidadania para o paciente em recuperação significa o resgate de uma rede social inexistente ou comprometida por decorrência da própria doença ou por motivos relacionais estabelecidos durante a vida, entre os quais, citam-se como exemplo a falta de comunicação clara e congruente, a indefinição de papéis, a ausência de regras e de limites, os conflitos e a presença de atitude agressiva (Fontes, 2007; Kern et al., 2009).

Dessa forma, o presente estudo objetivou descrever e analisar a rede social de pacientes com diagnóstico de esquizofrenia de um CAPS II, do Distrito Federal, Brasil.

\section{Métodos}

Estudo descritivo exploratório, dos campos da psicologia clínica e das ciências sociais. Utilizou-se a metodologia de Análise das Redes Sociais e a estratégia transformadora concomitante, na qual os dados quanti e qualitativos foram coletados e analisados ao mesmo tempo, o que caracterizou o método de estudo misto (Creswell, 2007; Silva, 2003).

Participaram da pesquisa portadores de esquizofrenia (entre 23 - 60 anos) diagnosticados por um médico psiquiatra e que, durante o período da coleta dos dados, estavam em tratamento neste CAPS II, localizado no Distrito Federal. Tendo em vista as peculiaridades do paciente esquizofrênico e as dificuldades encontradas, como as desistências (seja por vontade própria ou da família), as situações de comorbidade (critério de exclusão), o estado de crise de alguns pacientes e a impossibilidade de participação por motivos pessoais, a seleção dos participantes foi determinada mediante o contato direto do pesquisador em campo, de acordo com a disponibilidade dos pacientes.

Quanto ao aspecto comorbidade, os pacientes que apresentavam diagnósticos como $F$ 20,4 (depressão pósesquizofrênica), $F$ 20,8 (outras esquizofrenias) e $F 20,9$ (esquizofrenia não especificada), apesar de também estarem classificados em subtipos específicos de esquizofrenia, foram inseridos nos critérios de exclusão, tendo em vista a situação atual ou a tendência à comorbidade, fator que poderia influenciar no andamento do estudo (Dalgalarrondo, 2008).

Dessa forma, considerando-se os critérios de exclusão, a amostra foi composta inicialmente de 26 pacientes, entre os quais, nove não aceitaram participar do estudo ou desistiram no decorrer do mesmo, restando 17 participantes na amostra definitiva. A pesquisa ocorreu no período de agosto a novembro de 2010.

No primeiro encontro, foi solicitada ao usuário e ao familiar/ responsável legal a assinatura do 'Termo de Consentimento Livre e Esclarecido’. Ademais, utilizou-se a Escala de Satisfação 
do Suporte Social (ESSS), visando conhecer a percepção do paciente frente à sua rede social, sob quatro aspectos: satisfação com os amigos, intimidade, satisfação com a família e atividades sociais. A versão final dessa Escala é constituída por 15 afirmações que são apresentadas para autopreenchimento, a partir de uma escala de Likert com cinco posições, quais sejam: 'concordo tototalmente', 'concordo na maior parte', 'não concordo e nem discordo', 'discordo na maior parte' e 'discordo totalmente'. A escala permite ainda a obtenção de um escore global, correspondendo as notas mais altas a uma percepção de maior satisfação com o suporte social. Validada por Ribeiro (1999), possui relevância por dar ênfase e visibilidade à percepção de cada sujeito, estando ligada aos processos cognitivos e emocionais, assim como ao seu bem estar e à sua qualidade de vida.

No segundo encontro, foi realizada a construção dos mapas de rede pelos pacientes. Ao mesmo tempo, foram preenchidos pela pesquisadora os questionários 'Gerador de Nomes e Qualificador do Apoio Social' e 'Gerador de Atributos para o Vínculo', com o intuito de incrementar as informações acerca dos membros citados em cada rede e de facilitar a organização e a análise dos dados. Tais questionários foram elaborados pela pesquisadora com base nas características estruturais propostas por Sluzki (1997). Em acréscimo, foi solicitada a realização de um relato escrito sobre a sua rede de apoio social.

Com a finalidade de realização de registros fotográficos, cada participante efetuou a escolha de um ou mais membros de sua rede com o (s) qual (is) considerava ter maior afinidade ou proximidade. A partir disso, foram feitas visitas domiciliares, com vistas a efetuar tais registros, os quais foram precedidos da assinatura do 'Termo de Consentimento Livre e Esclarecido Para Uso da Imagem'. Esclarecemos que o registro fotográfico teve exclusivamente a finalidade documental.

No que se concerne à abordagem quantitativa, objetivouse analisar os dados de forma descritiva e com inferencial numérico estatístico. Para tanto, foi utilizado o seguinte programa de análise informatizado: Statistical Package for the Social Sciences 17.0 (SPSS). Referente à abordagem qualitativa, o material colhido foi descrito e analisado, com destaque para a metodologia do Discurso do Sujeito Coletivo (DSC) (Lefèvre \& Lefèvre, 2005, 2006).

A metodologia do DSC propõe possibilidades para expressar a opinião ou o pensamento coletivo por meio dos discursos individualizados de cada ator social. Os discursos da pesquisa foram redigidos na primeira pessoa do singular, com o intuito de transmitir e de expressar a opinião coletiva e representativa de todas essas vozes, o sujeito coletivo. O DSC caracteriza-se como uma técnica de representatividade qualitativa, onde a opinião coletiva é apresentada na forma de discurso; e como uma técnica quantitativa, quando indica quantos depoimentos, em número, foram precisos para compor o discurso coletivo (Lefèvre \& Lefèvre, 2005, 2006).

A pesquisa seguiu os preceitos éticos estabelecidos na resolução 196/96, do Conselho Nacional de Saúde/Ministério da Saúde, aprovada pelo Comitê de Ética em Pesquisa da Secretaria de Estado de Saúde do DF, sob o parecer de nº̄ . 220/2010 (Brasil, 1996).

\section{Resultados, análise e discussão}

O perfil mostrado na Tabela 1 confirma resultados anteriores (Barroso, Bandeira, \& Nascimento, 2007; Lauber, Eichenberger,

Tabela 1

Características Sociodemográficas e Clínicas da Amostra (\%). Distrito Federal, 2010.

\begin{tabular}{|c|c|c|c|}
\hline & & $\mathbf{n}$ & $\%$ \\
\hline \multirow[t]{2}{*}{ Sexo } & Masculino & 13 & 76,5 \\
\hline & Feminino & 4 & 23,5 \\
\hline \multirow[t]{4}{*}{ Faixa Etária } & $21-30$ & 4 & 23,5 \\
\hline & $31-40$ & 9 & 52,9 \\
\hline & $41-50$ & 1 & 5,9 \\
\hline & $51-60$ & 3 & 17,6 \\
\hline \multirow[t]{2}{*}{ Naturalidade } & Brasília, DF & 9 & 52,9 \\
\hline & Outras localidades & 7 & 41,2 \\
\hline \multirow[t]{3}{*}{ Estado Civil } & Solteiro (a) & 11 & 64,7 \\
\hline & Casado (a) & 4 & 23,5 \\
\hline & Separado (a) & 2 & 11,8 \\
\hline \multirow[t]{2}{*}{ Filhos } & Sem filhos & 12 & 70,6 \\
\hline & Com filhos & 5 & 29,4 \\
\hline \multirow[t]{5}{*}{ Residência } & Ceilândia & 7 & 41,2 \\
\hline & Taguatinga & 6 & 35,3 \\
\hline & Guará II & 2 & 11,8 \\
\hline & Águas Claras & 1 & 5,9 \\
\hline & Asa Sul & 1 & 5,9 \\
\hline \multirow[t]{5}{*}{ Coabitantes } & 2 pessoas & 8 & 47,1 \\
\hline & 3 pessoas & 4 & 23,5 \\
\hline & 4 pessoas & 2 & 11,8 \\
\hline & 5 pessoas & 2 & 11,8 \\
\hline & 9 pessoas & 1 & 5,9 \\
\hline \multirow[t]{5}{*}{ Escolaridade } & Fund. Incompleto & 7 & 41,2 \\
\hline & Fund. Completo & 1 & 5,9 \\
\hline & Ensino Médio & 6 & 35,3 \\
\hline & Superior Incompleto & 2 & 11,8 \\
\hline & Superior Completo & 1 & 5,9 \\
\hline \multirow[t]{4}{*}{ Ocupação } & Afastado do Trabalho & 7 & 41,2 \\
\hline & Sem Emprego & 5 & 29,4 \\
\hline & Dona de Casa & 3 & 17,6 \\
\hline & Autônomo & 2 & 11,8 \\
\hline \multirow[t]{3}{*}{ Religião } & Católica & 8 & 47,1 \\
\hline & Evangélico & 4 & 23,5 \\
\hline & Sem relato & 5 & 29,4 \\
\hline \multirow[t]{2}{*}{$\begin{array}{l}\text { Tipo de Esqui- } \\
\text { zofrenia }\end{array}$} & F 20 & 15 & 88,2 \\
\hline & F 20.5 & 2 & 11,8 \\
\hline
\end{tabular}

Fonte Própria. 
Luginbühl, Keller, \& Rössler, 2003), caracterizando a maioria em homens, solteiros e com baixa escolaridade.

Grande parte dos pacientes reside com familiares (16/94,11\%), o que corrobora com o estudo de Barroso et al. (2007), em que $84 \%$ dos familiares residiam com os pacientes. Em contrapartida, no estudo internacional de Tessler e Gamache (2000), apenas uma baixa percentagem (17\%) dos familiares cuidadores residiam com os pacientes. Em relação à afiliação religiosa, verificou-se que doze pacientes (70,56\%) encontramse ligados a uma religião, o que aumenta suas possibilidades de receber apoio proveniente da comunidade (Dalgalarrondo, Banzato, \& Botega, 2004; Meneses \& Sarriera, 2005).

As médias do tempo que os indivíduos possuem o diagnóstico da doença e do tempo de tratamento no CAPS II foram, respectivamente, de 35,58 meses e de 26,41 meses.

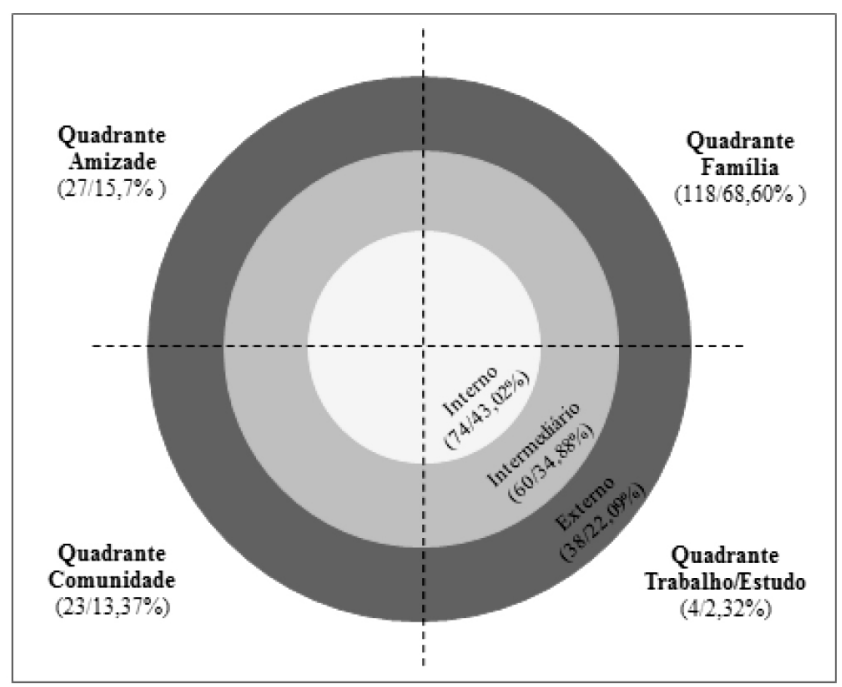

Nota: Fonte própria.

\section{Figura 1}

Distribuição Percentual dos Atores Sociais (AS) nos quadrantes e nos círculos do Mapa de Rede. Distrito Federal, 2010 .

De acordo com a figura 1, o mapa de rede foi organizado a partir da sobreposição das redes de apoio pessoal social de cada paciente. Os componentes das redes foram denominados de "atores sociais" (AS), segundo a metodologia de ARS. Os 17 informantes geraram o mínimo de três e o máximo de 19 (média: 10,12; DP: 4,67) nomes compondo a sua rede, gerando um total de 172 atores sociais nomeados. No trabalho de More (2005), com pacientes psiquiátricos, o tamanho da rede varia numa amplitude de seis pessoas e no mínimo cinco. Tal fato respalda o tamanho da rede em estudo, pois independente do tipo de relação estabelecida, existe o recebimento de algum tipo de apoio, o que é benéfico.

Observa-se que as redes pessoais, em sua maioria, apresentam uma distribuição predominante no quadrante 'família'. Segundo Sluzki (1997), tais redes são menos efetivas, gerando menos opções de receber apoio quando comparadas com redes de distribuição mais amplas, onde as pessoas que compõem a rede social daquele indivíduo fazem parte de outros quadrantes também, contribuindo assim para a divisão das responsabilidades, evitando a sobrecarga de alguns membros familiares. Geralmente, quando a rede significativa se centra na família, da qual dois membros se localizam no círculo interno das relações íntimas (tais como familiares diretos com contato cotidiano, e amigos próximos), e o resto no círculo intermediário das relações pessoais com menor grau de compromisso (tais como relações sociais ou profissionais com contato pessoal mas sem intimidade), possibilita ao indivíduo tornar-se muito dependente dessas duas pessoas centrais, e da família em geral. Speck (1989) inferiu que o fracasso frequente no tratamento a pacientes psiquiátricos obedecia ao fato de se trabalhar com uma população extremamente restrita - a família.

A variável composição contempla a localização nos círculos, caracterizando a proximidade das relações segundo a percepção do paciente, seja afetivo ou fisicamente. Nesse contexto, onde se percebe uma maior distribuição no círculo interno cabe ratificar o entendimento de Sluzki (1997), o qual aponta que redes muito localizadas, conferem menos oportunidades de apoio. Os pacientes tornam-se dependentes dessas pessoas mais próximas.

Em que pese uma maior distribuição no círculo interno, foi possível notar, por meio do estudo aprofundado de cada relação, que somente uma ou no máximo duas pessoas das citadas mantinham, efetivamente, um contato mais íntimo e com mais disponibilidade de oferecer apoio. Contudo, deve-se atentar para as dificuldades dos pacientes esquizofrênicos em classificar o tipo de relação estabelecida com o outro, associadas ao prejuízo das funções cognitivas, reflexo do adoecimento psíquico.

Verifica-se o grande número de conexões estabelecidas entre os atores da rede, traduzindo-se numa rede com alta densidade, predominando as relações familiares. De acordo com Sluzki (1997), uma alta densidade não é benéfica, pois favorece a conformidade, aumenta a pressão frente às regras do grupo e possibilita exclusão e isolamento.

Nesse sentido, destaca-se a necessidade de promoção de apoio proveniente da comunidade e das relações de trabalho e de estudo, com vistas a minimizar a sobrecarga familiar evidenciada pela forte fotografia da imensa quantidade de apoio disponibilizada pela instituição família. Palestras informativas poderiam ser realizadas por agentes de saúde mental, habilitados e experientes, nos núcleos das comunidades e nos ambientes de trabalho e de estudo, com enfoque na Saúde Mental e na necessidade de colaboração de todos.

Do quantitativo de pessoas referenciadas no quadrante 'comunidade' da rede social total $(23 / 13,37 \%), 11$ pertencem aos serviços de saúde, sendo nove profissionais deste CAPS II. Por outro lado, pode ser um dado relevante, 12 informantes (70,58\%) não incluíram em seus mapas de rede os profissionais do CAPS II, o que pode denotar uma baixa influência na percepção dos mesmos. Segundo More (2005), a relevância do papel profissional de saúde está, ainda, na detecção dos atores sociais citados na rede de cada paciente e no contato junto aos mesmos, com o intuito de informá-los quanto à importância da função que exercem e de contribuir para o processo de tratamento, possibilitando a promoção da saúde e dos potenciais envolvidos numa rede. 
A nova proposta de saúde mental se coaduna com esse entendimento, impondo a construção de redes de apoio social, a fim de acolher a pessoa em sofrimento psíquico, dar sentido à sua subjetividade e educá-lo acerca do seu papel de cidadão.

Neste CAPS II existe a função do técnico de referência, profissional que, por manter um vínculo de maior proximidade com certos pacientes, assume a responsabilidade de verificar, constantemente, como eles estão quanto à adesão aos grupos terapêuticos, ao tratamento, às idas ao psiquiatra, à medicação e a outros assuntos que dizem respeito à vida fora desta instituição. Entretanto, é provável que se essa função fosse exercida de forma mais eficiente, os resultados apareceriam diferentes, os profissionais seriam lembrados com maior evidência, o que poderia indicar a diminuição da sobrecarga familiar identificada. (Tabela 2)

Observa-se, na tabela 2, na qual se mostra a correlação entre a procedência e a função do apoio social, que foram citadas 476 oportunidades de apoio social, tendo $327(68,69 \%)$ procedência

Tabela 2

Características Estruturais: Correlação entre a Procedência e a Função do Apoio Social das Citações Feitas pelos Informantes. Distrito Federal, 2010.

\begin{tabular}{ccccccc}
\hline $\begin{array}{c}\text { Procedência } \\
\text { Função }\end{array}$ & Família & Amizade & Comunidade & $\begin{array}{c}\text { Sistema de } \\
\text { Saúde }\end{array}$ & Trabalho/Escola & TOTAL \\
\hline Companhia Social & 79 & 31 & 4 & 5 & 2 & 121 \\
Apoio Emocional & 67 & 21 & 7 & 10 & 2 & 107 \\
Guia Cognitivo e de Conselhos & 52 & 13 & 4 & 5 & 7 & 0 \\
Regulação Social & 54 & 7 & 1 & 5 & 0 & 58 \\
Ajuda de Material e de Serviços & 38 & 2 & 2 & 4 & 0 & 55 \\
Acesso a Novos Contatos & 37 & 12 & & & 50 \\
\hline
\end{tabular}

Fonte Própria.

na família, $86(18,06 \%)$ nos amigos, $38(7,98 \%)$ nos profissionais de saúde, $20(4,20 \%)$ na comunidade e cinco $(1,05 \%)$ nas relações estabelecidas no ambiente trabalho/escola. Barroso et al. (2007) destacaram uma elevada sobrecarga subjetiva e objetiva na maioria dos familiares, no que diz respeito, principalmente, à supervisão dos comportamentos problemáticos dos pacientes, às preocupações com sua segurança e futuro e à passividade demonstrada pelos pacientes em ocupar seu tempo. Nesse sentido, ressalta-se a necessidade de equilibrar, em números, a procedência do apoio, a fim de evitar essa sobrecarga da família e propiciar bem-estar e qualidade de vida para todos os envolvidos.

Em relação à função do apoio social, houve predominância do apoio 'companhia social' e 'apoio emocional' frente aos demais. Segundo More (2005), trata-se de apoios de cuidado, em que o outro se dispõe para a relação, favorecendo o contato pleno e a realização de atividades conjuntas. Possibilitam que os pacientes sejam compreendidos e estimulados.

A partir da ESSS, foram mensurados o escore da escala global, bem como a média e o desvio padrão nos diferentes domínios, conforme apresentados na tabela 3.

Tabela 3

Média e Desvio Padrão das Diferentes Subescalas da ESSS e Escore da Escala Global. Distrito Federal, 2010.

\begin{tabular}{ccccc}
\hline $\begin{array}{c}\text { Escala Global } \\
\text { Subescalas }\end{array}$ & $\mathbf{N}^{\mathbf{0}}$ Itens & Amplitude & M & DP \\
\hline Satisfação com os Amigos (AS) & 5 & $5,00-25,00$ & 14,05 & 5,11 \\
Intimidade (IN) & 4 & $4,00-20,00$ & 10,35 & 3,4 \\
Satisfação com a Família (SF) & 3 & $3,00-15,00$ & 11,35 & 3,83 \\
Atividades Sociais (AS) & 3 & $3,00-15,00$ & 5,64 & 2,76 \\
Escala Global (ESSS) & 15 & $15,00-75,00$ & 41,41 & 8,86 \\
\hline
\end{tabular}

Fonte Própria.

A ESSS classifica o nível de satisfação com o suporte social em: alto (51-75 pontos), médio (26-50 pontos) e baixo (até 25 pontos). O escore da global foi de 41,41, o que, de acordo com Baptista, Baptista e Torres (2006), representa um nível médio de satisfação com o suporte social. O estudo de Rodrigues (2008) com indivíduos com perturbação psiquiátrica, demonstrou um nível de satisfação semelhante, o que corrobora os resultados encontrados.

Em análise mais aprofundada da ESSS foi observado que a maioria demonstra satisfação com as atividades e coisas que realizam com os amigos (76,47\%), e com o tipo de amizades $(58,83 \%)$, todavia gostariam de ser mais procurados e solicitados pelos mesmos $(88,24 \%)$. Encontram-se pouco satisfeitos com a quantidade de amigos que possuem $(52,94 \%)$ e com a quantidade de tempo que passam juntos $(58,82 \%)$, entretanto percebem que suas limitações interferem no estabelecimento de vínculos (88,23\%). Segundo Speck (1989), os vínculos de amizade possuem grandes possibilidades de desempenhar um papel significativo junto a tal paciente, visto que o pouco tempo despendido ao lado deles não permite gerar conflitos como 
acontece nas relações entre familiares.

A seguir, listam-se as falas dos atores sociais participantes da pesquisa como forma de descrever suas expressões com relação aos temas evidenciados acima: satisfação com o tipo de amigos que tem; satisfação com atividades e coisas que realizam com amigos; pouca satisfação quanto ao número de amizades e quanto ao número de vezes que os amigos os procuram.

- Satisfação com o tipo de amigos que tem: "Ela é bastante companheira sabe fazer amizade, é carinhosa, é uma pessoa bem delicada. Foi por acaso, começamos a conversar numa terapia de apresentação e a partir daí ficamos amigas (...)" (AS-2, comunicação pessoal, Setembro 8, 2010).

- Satisfação com atividades e coisas que realizam com amigos: “(...) e tenho amigo e amiga fora de casa são os vizinhos que está sempre presente e leva para a Igreja e sempre comunica e eu quero fazer mais amigos (...)" (AS-1, comunicação pessoal, Setembro 8, 2010).

- Pouca satisfação quanto ao número de amizades e quanto ao número de vezes que os amigos os procuram: “(...) tô satisfeito mais podia ser melhor podia ter mais amigos, ter com que contar mais o que tem pessoas eu desabafar pessoas unidas comigo amigos fiel (...)" (AS-5, comunicação pessoal, Setembro 8, 2010).

- Percebem suas limitações em estabelecer vínculos de amizades: “(...) eu acho que posso ter mais amigos, mas eu acho que eu fecho para as pessoas" (AS-10, Setembro 8, 2010).

Percebe-se que a maior parte se sente só no mundo e sem apoio (52,94\%); quando precisa desabafar com alguém não encontra facilmente amigos com quem o fazer $(41,18 \%)$; não possui várias pessoas a quem possa pedir socorro em caso de emergência (47,06\%); às vezes sente falta de alguém verdadeiramente íntimo com quem possa desabafar sobre coisas íntimas (76,47\%). Verifica-se que a mãe, em primeiro lugar, ou algum membro familiar aparece como a figura que estabelece esse laço mais forte, mais íntimo e capaz de proporcionar segurança e proteção ao paciente, o que é corroborado por estudos de Lauber et al. (2003) e Barroso et al. (2007). Essa tendência pode ser confirmada no presente estudo a partir dos registros fotográficos efetuados, quando os pacientes escolheram a pessoa mais importante e mais representativa para estar ao lado deles. Nove pacientes $(52,94 \%)$ escolheram a mãe, sete $(41,17 \%)$ optaram por algum membro da família, um $(5,8 \%)$ selecionou um amigo e outro $(5,8 \%)$ decidiu ser fotografado sozinho.

- Mãe representando a figura de maior intimidade:

(...) eu e minha mãe a gente é unida em momento bom ou ruim. Tem momentos que a gente desabafa em falar um com outro, o que sente, o que pensa, o que acha. A gente da opinião uma a outra, minha mãe me dá conselho, minha mãe me ajuda em certos momentos (...)" (AS-5, comunicação pessoal, Setembro 8, 2010).

Observa-se um acentuado nível de satisfação com a família, com a forma de se relacionar $(70,59 \%)$, com a quantidade de tempo que passam juntos $(64,70 \%)$ e com as atividades que realizam em conjunto $(64,71 \%)$, todavia verifica-se certa insatisfação com a forma de se relacionar $(17,64 \%)$, com a quantidade de tempo que passam juntos $(23,53 \%)$ e com as atividades que realizam em conjunto (17,64\%). Tais fatos, apesar de caracterizarem uma pequena parte da amostra, evidenciam um mal-estar comum que pode ser justificado pela grande proximidade da família, alta densidade das relações e grande exigência de suporte familiar por parte dos pacientes. Com isso, familiares atuam desenvolvendo múltiplas funções na vida dos pacientes, ou seja, como multifuncionais, o que pode gerar em si mesmos sobrecarga, conflitos e estresse (Sluzki, 1997; Speck, 1989).

Percebe-se certa insatisfação com as atividades sociais, com a quantidade de vezes que saem com amigos $(87,23 \%)$, com a falta de atividades sociais que os satisfaçam $(82,35 \%)$ e com a falta de atividades sociais de organizações (partidos políticos, clubes, Igreja, times desportivos, etc) $(58,82 \%)$. Apesar dos resultados demonstrados, é digno de nota relatar que os pacientes encontram-se inseridos em atividades sociais realizadas no CAPS II (Oficinas, Grupos Terapêuticos, Atividade Física, Grupos de Expressão, entre outros). Porém, diante dessa percepção que retrata a insuficiência desse tipo de atividades, pensa-se na possibilidade de revisão dos planos terapêuticos, respeitando a singularidade e especificidade de cada caso, assim como as limitações estruturais da própria instituição. No estudo de Barroso et al. (2007), constata-se que as restrições do lazer e de atividades sociais são as principais alterações na vida dos familiares e que tais restrições geram elevada sobrecarga nesses familiares.

Nos relatos abaixo, quando pacientes apresentam capacidade de almejar planos, traçar objetivos e de se inserir socialmente, percebe-se alguma melhora dos mesmos:

- Almejam autonomia e inserção social:“(...) tô satisfeito, mas podia ser um pouco diferente eu arrumar um emprego e trabalhar, entrar na faculdade, assim podia ter um tratamento normal e ficar sem remédios (...)”, (AS-17, comunicação pessoal, Setembro 17, 2010).

Em relação à rede de apoio total, observa-se que os pacientes apresentam maior facilidade para retribuir o apoio recebido quando tem procedência na família.

- Reciprocidade:

(...) ajudo minha mãe na limpeza da casa (...). Eu rezo para ela ter muita saúde e dar a lição antiga quando ela precisar porque ela já lutou muito na vida e agora ela precisa se descansar e passear e curtir a vida" (AS-10, Setembro 15, 2010).

Percebe-se a reciprocidade em dar e receber apoio, o que gera aumento da autoestima, estimula a auto valorização, tornando presente o sentimento de se sentir útil. Observou-se a melhora dos pacientes no que diz respeito a reconhecer o esforço do outro no apoio prestado.

- Percebem o esforço do outro no apoio prestado: “(...) elas faziam rodízio, quando não era a XX que me trazia era a XY e agora é a XZ. Elas me levavam e me traziam para cá e isso eu achava importante" (AS-2, Setembro 8, 2010).

\section{Considerações finais}

Observou-se que muitos dos pacientes conseguem retribuir o apoio recebido, especialmente para os membros da família, 
com os quais são capazes de estabelecer vínculos mais íntimos, fato que evidencia uma mudança motivadora para todos os envolvidos. Estender essa reciprocidade para os outros membros da rede (amigos, vizinhos, profissionais, entre outros) poderia ser uma proposta a ser desenvolvida e trabalhada pelos próprios profissionais deste CAPS, a fim de fortalecer as relações para além do âmbito familiar.

Os programas de saúde mental para pacientes com transtornos psíquicos graves e persistentes devem procurar atender a essa demanda, com o intuito de possibilitar que a atenção ofertada para esses pacientes não seja de inteira responsabilidade das famílias.

O desenvolvimento de atividades ocupacionais e recreativas para esses pacientes nos centros de atenção psicossocial poderia funcionar como um fator de redução da sobrecarga familiar. Somado a isso, seriam benéficas intervenções com os próprios familiares sobre como lidar com os comportamentos problemáticos dos pacientes ou sobre o modo de lhes propiciar momentos agradáveis, em que possam também se sentir cuidados.

Recomenda-se a revisão dos planos terapêuticos, a implantação de grupos psicoeducativos para pacientes e famílias, visitas domiciliares e auxílio para o desenvolvimento de estratégias de enfrentamento da sobrecarga familiar. Nesse sentido, tornam-se fatores indispensáveis a organização da rotina dos profissionais, a fim de diminuir a evasão dos mesmos e favorecer a motivação no tratar e cuidar desses pacientes, bem como a responsabilização do técnico de referência em acompanhar seus pacientes, visto que se trata de uma população frágil e necessitada de escuta, de cuidado e, por que não dizer, de carinho e de amor.

Entretanto, é preciso considerar as limitações do estudo. Um aspecto diz respeito às normatizações dos instrumentos utilizados, pois se encontrou informações incompletas acerca da aplicação, definição dos termos e parâmetros de julgamento para conclusões, cedidas pelos próprios autores, seja em seus livros, ou em artigos de validação dos mesmos. Também se precisam relativizar os resultados em função do tamanho da amostra, muito embora ela possa ser considerada representativa para a população eleita, usuários de um CAPS.

Apesar de os participantes apresentarem um nível médio de satisfação com o suporte social, infere-se que o apoio e a motivação devem estar constantemente presentes, a fim de manter ou aumentar o nível de satisfação de acordo com as necessidades apresentadas em cada uma destas áreas: família, amizade, intimidade e atividades sociais.

Em face do presente estudo, verifica-se que é viável, por meio da avaliação das redes de apoio social, reconhecer as limitações dos pacientes portadores de esquizofrenia e identificar as potencialidades de melhorias. A partir disso, é possível favorecer um incremento dos vínculos relacionais e uma amplificação da consciência e da sensibilidade de cada membro da rede acerca de sua função de apoio, o que, em última análise, promove saúde e bem-estar.

A relevância do estudo da rede social do paciente esquizofrênico está em explorar um campo ainda bastante desconhecido e em empreender uma aproximação entre as várias realidades existentes nessas redes de apoio. A valorização de uma cultura participativa, não somente dentro das instituições, mas em todos os contextos nos quais se encontram inseridos os portadores de esquizofrenia, pode contribuir, sobremaneira, para o aumento da autonomia e da autoestima dos mesmos.

Com base nas prevalências, espera-se que a pesquisa possa incentivar a implementação de avanços teóricos (por meio de pesquisas e estudos descritivos e exploratórios como este) e de métodos de investigação (na melhoria de instrumentos tanto para a coleta, quanto para a análise dos dados) que auxiliem no entendimento de como o apoio social atua na vida das pessoas com diagnóstico de esquizofrenia, assim como no planejamento e na organização de intervenções, visando à promoção de saúde, ao bem-estar, à qualidade de vida, e à reabilitação psicossocial.

\section{Referências}

Adrados, I. (1982). Manual de psicodiagnóstico e diagnóstico diferencial. Petrópolis: Vozes.

Baptista, M. N., Baptista, A. S. D., \& Torres, E. C. R. (2006). Associação entre suporte social, depressão e ansiedade em gestantes. Psicologia, Ciência e Profissão, 7(1), 39-48. doi: 10.1590/S1414-98932008000400016

Barlow, D. H., \& Durand, V. M. (2008). Psicopatologia: Uma abordagem integrada (4a ed.). São Paulo: Cengage Learning.

Barroso, S. M., Bandeira, M., \& Nascimento, E. (2007). Sobrecarga de familiares de pacientes psiquiátricos atendidos na rede pública. Revista de Psiquiatria Clínica, 34(6), 270-277. doi: 10.1590/S0101-60832007000600003

Brasil (1996). Resolução nº 196 de 10 de outubro de 1996. Regulamenta diretrizes e normas de pesquisas envolvendo seres humanos.

Creswell, J. W. (2007). Projeto de pesquisa-Métodos qualitativo, quantitativo e misto (2a ed.). Porto Alegre (RS): Artmed.

Dalgalarrondo, P. (2008). Psicopatologia e semiologia dos transtornos mentais (2 $\underline{a}$ ed.). Porto Alegre: Artmed.

Dalgalarrondo, P., Banzato, C. E. M., \& Botega, N. J. (2004). Frequência aumentada de esquizofrenia em pacientes evangélicos internados. Jornal Brasileiro de Psiquiatria, 53(3), 143-152.

Duarte, P. V. (2010). Redes sociais. Prevenção ao uso indevido de drogas: Capacitação para conselheiros e lideranças comunitárias. Brasília (DF): SENAD.

Fontes, B. A. S. M. (2007). Redes sociais e saúde: Sobre a formação de redes de apoio social no cotidiano de portadores de transtorno mental. Política \& Trabalho - Revista de Ciências Sociais. 26, 87-104.

Foucault, M. (1984). Doença mental e psicologia (2a ed.). Rio de Janeiro: Tempo Brasileiro.

Foucault, M. (1999). Problematização do sujeito: Psicologia, psiquiatria e psicanálise. Rio de Janeiro: Forense Universitária.

Gabbard, E., Beck, J., \& Holmes, J. (2007). Compêndio de psicoterapia de Oxford. (M. F. Lopes \& R. C. Costa, Trads.). Porto Alegre: Artmed.

Kern, R. S., Glynn, S. M., Horan, W. P., \& Marder, S. R. (2009). Psychosocial treatments to promote functional recovery in schizophrenia. Schizophrenia Bulletin, 35(2), 347-361.

Landim, F. L. P., Comaru, J. D. L., Mesquita, R. B. D., \& Collares, P. M. (2006). Redes sociais informais no cotidiano das famílias de uma comunidade da periferia de Fortaleza. Cogitare Enfermagem, 11(1), 16-23.

Lauber, C., Eichenberger, A., Luginbhl, P., Keller, C., \& Rössler, W. (2003). Determinants of burden in caregivers of patients with exacerbating schizophrenia. European Psychiatry, 18(6), 285-289. doi: 10.1016/j. eurpsy.2003.06.004

Lefèvre, F. (2006). O sujeito coletivo que fala. Interface-Comunicacão, Saúde, Educação, 10(20), 517-24. doi: 10.1590/S1414-32832006000200017 
Lefèvre, F., \& Lefèvre, A. M. C. (2005). O discurso do sujeito coletivo: Um novo enfoque em pesquisa qualitativa. Caxias do Sul: Educs.

Macpherson, M. (2009). Psychological causes of schizophrenia. Schizophrenia Bulletin, 35(2), 284-286. doi: 10.1093/schbul/sbn179

Meneses, M. P. R., \& Sarriera, J. C. (2005). Redes sociais na investigação psicossocial. Aletheia, 21, 53-67.

More, C. O. O. (2005). As redes pessoais significativas como instrumento de intervenção psicológica no contexto comunitário. Paidéia (Ribeirão Preto), 15(31), 287-297. doi: 10.1590/S0103-863X2005000200016

Onocko-Campos, R. T., \& Furtado, J. P. (2006). Entre a saúde coletiva e a saúde mental: Um instrumental metodológico para avaliação da rede de Centros de Atenção Psicossocial do SUS. Caderno de Saúde Pública, 22(5), 1053-1062. doi: 10.1590/S0102-311X2006000500018

Patterson, T. L., \& Leeuwenkamp, O. R. (2008). Adjunctive psychosocial therapies for the treatment of schizophrenia. Schizophrenia Research. Department of Psychiatry, University of California, San Diego (CA), USA. doi: 10.1016/j. schres.2007.12.468

Paulin, L. F., \& Turato, E. R. (2004). Antecedentes da reforma psiquiátrica no Brasil: As contradições dos anos 1970. História, Ciências, Saúde, 11(2): 241-58, maio-ago. Manguinhos. doi: 10.1590/S0104-59702004000200002

Ribeiro, J. L. P. (1999). Escala de satisfação com o suporte social. Análise Psicológica, 3(17), 547-558.

Rodrigues, V. D. B. (2008). Satisfação com o suporte social em indivíduos com perturbação psiquiátrica: estudo exploratório. (Monografia). Recuperado de http://hdl.handle.net/10284/1004
Rüesch, P., Graf. J., Meyer, P. C., Rössler, W., \& Hell, D. (2004). Occupation, social support and quality of life in persons with schizophrenic or affective disorders. Society Psychiatry Epidemiology, 39, 686-694. doi:10.1007/ s00127-004-0812-y

Silva, M. C. M. D. S. (2003). Redes sociais intraorganizacionais informais e gestão: Um estudo nas áreas de manutenção e operação da planta HYCO8, Camaçari-BA (Dissertação de Mestrado). Recuperado de http://www. adm.ufba.br/pt-br/publicacao/redes-sociais-intraorganizacionais-informaisgestao-estudo-areas-manutencao-operacao

Sluzki, C. E. (1997). A rede social na prática sistêmica: Alternativas terapêuticas. São Paulo: Casa do Psicólogo.

Speck, V. R. (1989). La intervención en red social: Las terapias de red, teoria y desarrollo. In: la práctica de la terapia de red. Barcelona: Gedisa.

Tenório, F. (2001). A psicanálise e a clínica da Reforma Psiquiátrica. Breve história da Reforma Brasileira. Rio de Janeiro: Rios Ambiciosos.

Tenório, F. (2002). A reforma psiquiátrica brasileira, da década de 1980 aos dias atuais: história e conceitos. História, Ciência, Saúde, 9(1): 25-59, jan.-abr. 2002. doi: 10.1590/S0104-59702002000100003

Tessler, R. C., \& Gamache, G. M. (2000). Family experiences with mental illness. Auburn House, Westport.

WHO. (1996). Composite International Diagnostic Interview. Geneva, Switzerland: World Health Organization.

Zelst, C. V. (2009). Stigmatization as an Environmental Risk in Schizophrenia: A User Perspective. Schizophrenia Bulletin, 35(2), 293-296. doi: 10.1093/ schbul/sbn 184

Tereza Efigênia Pessoa Morano Macêdo, graduada em Psicologia pela Universidade Católica de Brasília (UCB), graduada em Educação Física pela Universidade de Fortaleza (UNIFOR), especializanda em Psicologia Clínica na área da Gestalt-Terapia pelo Instituto de Gestalt-Terapia de Brasília (IGTB), especialista em Educação Física Escolar pela Faculdade Farias Brito (FFB), é aluna de pesquisa pela Universidade Católica de Brasília (UCB). Endereço para correspondência: Rua Antonio Augusto, 852. Apartamento 701. Ed. Terra Brasilis. Bairro Meireles. Fortaleza-CE. E-mail: tecamorano@hotmail.com

Cibelle Antunes Fernandes, mestre em Psicologia Clínica pela Universidade de Brasília (UNB), doutoranda em Psicologia Clínica pela Universidade de Brasília (UNB), é Professora Assistente II da Universidade Católica de Brasília (UCB) e é coordenadora de estágio do curso de Psicologia da Universidade Católica de Brasília (UCB). E-mail: cibelle@ucb.br

Ileno Silva da Costa, doutor em Psicologia Clínica pela Universidade de Brasília/University of Warwick, é Professor Adjunto do Departamento de Psicologia Clínica da UnB, é coordenador do Centro de Atendimento e Estudos Psicológicos-CAEP/IP/UnB (2001-2010), é coordenador do Grupo de Intervenção Precoce nas Psicoses (GIPSI), é vice-diretor do Instituto de Psicologia da UnB (2010-2012), é coordenador de extensão do Instituto de Psicologia (2010-2012) e coordenador de pós-graduação Lato Sensu do IP (2013-...). E-mail: ileno@unb.br 